\title{
Antecedents of Social Network Trust in SNS Usage: The Moderating Role of Offline Familiarity
}

\author{
Yu Wang \\ School of Government Management, Beijing Normal University, Beijing, China \\ Email: 925954923@qq.com
}

How to cite this paper: Wang, Y. (2017) Antecedents of Social Network Trust in SNS Usage: The Moderating Role of Offline Familiarity. Social Networking, 6, 107-134. https://doi.org/10.4236/sn.2017.62007

Received: February 14, 2017

Accepted: April 10, 2017

Published: April 13, 2017

Copyright $\odot 2017$ by author and Scientific Research Publishing Inc. This work is licensed under the Creative Commons Attribution International License (CC BY 4.0).

http://creativecommons.org/licenses/by/4.0/

\section{(c) (i) Open Access}

\begin{abstract}
With the rapid development of social networks, there is a focus on marketing strategies and business models that are based on social media. In the academic world, scholars believe that online trust is a key factor contributing to online purchasing behavior. This article explored several factors in social media trust and verified the moderating role of offline familiarity by using relevant research on online trust in conjunction with a structure equation model. The results show that independent variables such as reputation, SNS interaction, information quality, reciprocity, satisfaction and shared values have a positive influence on trust, whereas perceived similarity does not, and information quality is the most important factor. In addition, offline familiarity significantly moderates the relations between information quality, reciprocity, reputation, shared values and social media trust. This information is important to assist companies in developing an effective social network marketing strategy.
\end{abstract}

\section{Keywords}

Offline Familiarity, Social Network, Trust, Moderate, Structure Equation Modeling

\section{Introduction}

Social network service (SNS) popularity has changed not only how people communicate in everyday life but also how people obtain new knowledge and information. People tend to acquire reliable information when they want to purchase new products through trusted professional websites or trusted friends on social networks. With the commercial development of new functions and applications on Facebook, SNS has made it possible for companies to develop marketing strategies and sell their products. Advertisers also have discovered a huge op- 
portunity to increase sales and brand awareness through social networks; this is called social commerce through SNS. Companies such as Apple, Amazon, and Best Buy established Facebook stores to sell their products and services to promote content marketing and brand marketing; this has led to profits and value that relies on interactions between SNS members. Currently, anyone can establish his/her own Facebook store. People can share promotion information and other users' experience on SNS with friends and promote sales relying on friends' relationships with others.

Social commerce will function well only when the interpersonal trust between members on SNS has been well developed. According to the Nelson global trust survey, $92 \%$ of the customers in the world tend to believe trusted channels, such as advice from best friends and recommendations from family members. This number has increased by $18 \%$ since 2007 . There is no doubt that SNS has the great motivational power because of its simple and convenient functions. Researchers have confirmed that social network trust among members will positively impact purchasing behaviors in social commerce. Kim and Ferrin (2008) have found that trust has a positive influence on purchasing behavior on B2C websites, and Chiu and Hsu (2012) have verified that trust positively impacts sustained purchasing behavior. We can easily derive a conclusion that social network trust and stable relationships are critical to social commerce.

The problem comes that what kind of people is trustworthy in SNS, especially those who sell products and services in SNS. When we need buy things in the Ecommerce platform, product quality, sellers' reputation and brand value come into our sights. If we do this in SNS and have no idea of the goods itself, purchase decision will mainly focus on the sellers' reliability. We will consider a wide range of factors, such as reputation, information quality, interaction frequency, self-disclosure, reciprocity. The weird thing is that antecedents in SNS depend on offline familiarity between one and another. For example, workmates who communicate with each other in office but not so often in SNS recommend others a new PC; people will be pleased to have a try when they need. But people will examine professionalism of online friends when we make decision.

The difference can be explained with two types of relationships: relationships based on reality and relationships based on virtualization. Relationships based on reality means that people develop relationships because of blood ties, region ties or work ties to individuals such as their parents, brothers and sisters, spouse, best friends and intimate workmates. A relation based on virtualization means that people make friends with those who they do not know in the real world and become acquainted with each other for reasons such as common hobbies and interests, similar backgrounds, shared experiences and information in SNS. A different type of relationship may lead to different types of trust development mechanisms. People are familiar with those who are real friends in reality; therefore, they may not care about how frequently they interact with them and what content they have released. These individuals are simply trusted. However, more information may be needed when a person decides whether 
he/she should trust strangers when one is offline; this information includes information quality, values, interaction ties and reciprocity. The more one is unfamiliar with a person, the more factors should be considered.

Then the second problem is whether offline familiarity really plays a key role to explain the difference? And the third problem, whether it has an impact on most antecedents of SNS trust?

In order to study the above three questions, this study is constructed as follows. First, it will begin with a literature review on online trust and introduce trust-building model. Second, build the conceptual framework and examine antecedents that can influence social network trust, and then derive the research hypotheses. In the third part, this research will conduct an empirical analysis to demonstrate whether the moderating effect of offline familiarity exists in the relation between antecedents and trust on Chinese SNS users, Wei Bo are chosen as the subject of analysis. Finally, discuss the results and give the conclusion, with the limitations and future research.

\section{Literature Review}

\subsection{Trust-the Definitions of Social Network Trust}

Trust has been studied in a variety of social science disciplines, and this has resulted in the numerous definitions for the term [1]. Psychologists, sociologists and others have discussed several forms of trust relationships as they occur in the offline world [2] [3] [4] [5]. Additionally, most definitions are for traditional offline interpersonal trust. Prior offline trust findings appear to be applicable to an on-line environment because offline and on-line situations have much in common. One obvious commonality is exchange. In settings, risk, fear, complexity and costs restrict exchange. Furthermore, the social rules of interaction between people appear to function in both the offline and on-line environment. Thus, offline trust research is relevant to on-line trust [6]. Our understanding of on-line trust should also develop offline definitions of trust [6].

Mayer et al. (1995) provide the trust definition: "the willingness of a party to be vulnerable to the actions of another party based on the expectation that the other will perform a particular action important to the trustor, irrespective of the ability to monitor or control that other party" (p. 712) [5]. This definition is mainly based on interpersonal trust, with no consideration of the risk characteristics of the internet, which is particularly salient in the on-line environment, and is unable to explain online trust completely. Corritore et al. (2003) define online trust as "an attitude of confident expectation in an online situation of risk that one's vulnerabilities will not be exploited" [6] [7]. The key concepts of this definition are risk, vulnerability, expectation, confidence and exploitation; these provide a relatively better interpretation of online trust. Past research primarily discusses online trust with websites, internet venders, and virtual community members. There is less research on social network trust between members; this is what we mainly focus on in this research, in contrast to the online trust of past studies. 
How does one provide a clear definition of social network trust? We use the modified definition proposed by Rotter (1967): "an expectancy held by an individual or a group that the word, promise, verbal or written statement of another individual or group can be relied upon in the course of interaction with participants in the social network situation of risk" [3].

Researchers have also agreed that trust is multidimensional, and the most cited three dimensions of trust are ability, integrity, and benevolence [5] [6]. However, certain researchers such as McKnight and Chervany (2001) believe that trust is composed of ability, benevolence, integrity, and predictability [8]. Opinion on the dimensions of trust is divided into different scholar groups; however, the previously stated trust composition is widely accepted.

Ability is skills or competencies that enable individuals or firms to demonstrate expertise in a certain area. Ability is domain-specific, and those with certain abilities are more likely to be trusted. For example, members who demonstrate the knowledge and skills to provide high quality services will attract more fans and prove capable of identifying member needs; in addition, fans want to take their advice regarding e-commerce service because they have gained members' trust.

Benevolence is the expectation that others (i.e., trusted parties) will have a positive orientation to achieve a value that is desirable in a relationship without rewards to the trustee. Benevolence expresses kindness and altruism Within SNS, the trustee reciprocates with appropriate advice and help, such as contributing to the ongoing discussion with the intent to help, support, and care for others. Benevolent members should at least actively respond to consumer questions [9] [10].

Integrity is the expectation that another will act in accordance with commonly accepted values, principles, and rules, such as not telling a lie and providing reasonably verified information [9] [10]. Integrity refers to righteous behavior. SNS may construct perceived integrity by imposing a code of ethical conduct, and thereby develop a perception of justice.

\subsection{Previous Research on Online Trust}

Since the development of the Internet, there has been considerable evidence that developing supportive interpersonal relationships online is important [11]. The most important component would be interpersonal trust between members online. Therefore, trust has been a common problem not only in reality but also in the virtual world. Currently, an increasing number of people want to communicate with friends online and purchase online. Since the 1990s, virtual communities' trust and E-commerce trust have also been hot research topics [12] [13]. Additionally, social network trust appeared later, when SNSs such as Facebook entered the internet world [14] [15] [16].

In e-commerce, online retailing or marketing has been an important channel or business model for many firms [17]. The main concern for online sellers is to motivate consumers to make repeat purchases through their online channels. 
Trust in sellers is a vital key to maintaining continuity in the buyer-seller relationship. [18] Therefore, trust has been long recognized as a critical success factor, and much research has been conducted on trust [8] [13] [17] [19] [20] [21]. Other studies indicate that people likely are not willing to purchase products from venders unless they hold positive beliefs and intentions [22]. Scholars have developed frameworks to verify how trust forms or progresses and to determine the relation between trust and behavioral intentions.

Moreover, trust is also critical for virtual communities (VC). In a virtual community, trust in members can be a major factor that affects the prosperity and success of VCs. On the one hand, previous literature suggests that the success of VCs requires that their members be willing to share their knowledge with other members and indicates that trust plays an important role in helping members overcome the problems regarding the motivation to share knowledge [1] [10]. On the other hand, participants are usually anonymous and do not engage in direct face-to-face communication; thus, trust could be a significant issue. In VCs, trust also plays an important role in affecting members' behavior because people will act more proactively when they trust the environment; this leads to more community stickiness and knowledge sharing.

Researchers have developed different classification schemes of VCs. The widely adopted four categories reidentified by Armstrong and Hagel (1996), including interest communities, fantasy communities, transaction communities, and relationship communities in which people with similar experiences come together and form meaningful personal relationships [23]. Sheldon (2009) and Grabner (2009) hold that the main motive to participate in SNS is relationship maintenance or social contact with people we know in real life [15] [16]. Relationship communities and social networks have this very common feature, which is developing relationships between members.

The concept of relationship communities blurs the boundary of virtual communities and social networks. Past research indicates that scholars directly use SNSs as VCs and believe that there is minimal difference in related online trust studies. SNS is one type of virtual community. Grabner (2009) find that the terms "online social network" and "virtual community" are often used synonymously in marketing-related literature [15]. Therefore, scholars have not strictly distinguished their differences.

Although similar, we cannot ignore the difference in service features, development mechanisms and bind ties. 1) A virtual community is generally anonymous, and an SNS is not anonymous. Therefore, members in a virtual community are always strangers in real life; conversely, SNSs are semi-real-name systems or more public. Anonymity relieves members from assuming the social responsibility and interpersonal burden that is shared in reality; as such, relatively unstable relationships with strangers can be developed as a stranger online. This feature makes members' inconsistent online and offline behavior normal. In contrast, a social network's name system will first insure identity consistency whether members are online or offline, which fosters the constraint of so- 
cial roles in reality and develops stable relationship. 2) Virtual communities work well dependent upon themes and topics, whereas SNS rely on social relationships. VCs will easily attract hundreds of people because of the entertainment, interesting topics, controversial themes or educational subjects provided to entice others to join in the community to meet needs that include knowledge sharing, acquiring knowledge, gaining social recognition or entertainment when bored; this means VCs are topic-centered. However, an SNS is a type of social network that caters to a broader audience and is primarily organized around people, not interests. Sheldon notes that the main motive for Facebook use is relationship maintenance or social contact with people users know in real life; the second reason is to pass the time when bored or to make new friends online [16]. Certain majors spend most of their time writing comments, scanning others' life progress and leaving messages when they use Facebook. 3) The bind tie strength developed in VC and SNS are different; VCs have weak ties and SNS have strong ties. Tie strength is a multidimensional construct that represents the strength of interpersonal relationships in the social network and is composed of closeness, intimacy, support, and association [15]. Strong ties are intimate relationships, e.g., with immediate family and close friends, and tend to be multi-stranded and regularly maintained. Conversely, weak ties are non-intimate relationships, e.g., with acquaintances, and tend to be single stranded and maintained infrequently. A considerable number of ties in SNSs can be characterized as strong ties because much of the contact in SNSs is between people who see each other in person more or less frequently. Conversely, VCs also support the formation of new connections with strangers, based on shared interests, political views, or activities, and thus builds and fosters weak ties between persons who are weakly tied, socially and physically distant, and not bound into densely knit work structures or a narrow circles of friends. Therefore, we derive a conclusion regarding research on VC and SNS.

\subsubsection{Antecedents of Online Trust}

There are several classifications for the antecedents to trust, one of which is based on the trust formation mechanism. Gefen et al. (2003b) classified the antecedents to trust into four types [24]: (1) knowledge-based trust, which focuses on trust building through repeated interactions; (2) cognition-based trust or initial trust, which focuses on trust building though first impressions rather than repeated interactions over a longer period of time; (3) institution-based trust, which focuses on relying upon an institution or third party to build trust; and (4) personality-based trust, which refers to individual personalities that influence trust building. Similarly, Kim et al. (2008) argue that there are four categories of antecedents that influence consumer trust towards electronic commerce entities: (1) Cognition-based, which are associated with consumers' observations and perceptions. (2) Affect-based, which are related to indirect interactions with the trustee. (3) Experience-based, which are related to the personal experiences of consumers with the vendor and internet shopping in general. (4) Personality-oriented, which are related to consumers' dispositional characteristics and 
stable nature [25].

Zucker (1986) identified three mechanisms to establish trust [26]: (1) processbased trust, which has similar meanings as knowledge-based trust; (2) characteristic based trust, which implies that trust is established based on social similarities, such as families, ethnicities, or racial origins; and (3) institution-based trust [23]. Other scholars such as Kim proposed a simple category after a careful review of the diverse trust antecedents, self-perception based and the transference-based forms of trust. Transference-based trust involves transference from a trusted "proof source".

Such classifications of trust antecedents are not applicable in this research. First, researchers study trust based on mechanisms of trust formation and categorize trust factors according to different perspectives; we may find it unclear without consideration of trust generation roles. Second, we need a comprehensive perspective to study trust, namely, the perspective from roles (trustor, trustee) and the trust generation process (interaction process between roles).

We provide a different view of classification. In traditional commerce, the trust-building process is affected by the characteristics of customers, salespersons, the company, and interactions between the two parties involved [25]; this is the same as trustor, trustee and interactions between them in VCs and on SNSs. Therefore, we finally form the following classifications, as Shankar (2002) noted [27]: (1) trustor-related factors, including mood and dispositional trust; (2) trustee-related factors, including ability, benevolence, integrity, reputation and predictability; and (3) interaction factors. We can add classifications such as cognition-based, affect-based and calculation-based. Cognition-based factors are composed of familiarity, confiding information, self-disclosure, shared value, experience, similarity, information quality, expertise and third-party guarantee. Affect-based factors involve SNS interaction and satisfaction. Calculation-based factors contain reciprocity, benefit attraction and perceived response.

\subsubsection{Theory Foundation-Trust Building Model}

Moorman et al. (1993) divided trust building into three stages: antecedents, process, and outcomes [12]. Antecedents of trust refer to elements that determine the formation of trust. Process means trust, which is demonstrated in the confidence of trustees' benevolence, ability, integrity, and predictability in uncertain circumstances [10]. Outcomes mainly refer to the behavioral intentions of members. This model is widely used in virtual community trust research [9] [23] [28].

McKnight et al. (2002a) proposed an e-commerce initial transaction trust building model (TBM) [13]. This model explained how consumers trust online sellers and explained consumers' behavioral intentions after trust has been built. TBM consist of three parts: antecedent factors, trust and behavioral intentions. Antecedents are composed of trust-building levers such as reputation, information quality, and institutional/structural factors such as structural assurance and perceived risk. Trust means trust in a vender. Behavioral intention refers to the intention to follow a vender's advice, the intention to share personal information 
on the web, and the intention to purchase from sites. This model is accepted and applied by several scholars in E-commerce trust research [21] [23] [29].

Butler (1991) believed that it was meaningful and useful to study how trust occurred and to measure the consequences of trust so that this could be applied to promote profit that relies on an appropriate marketing strategy [30].

In this research, having consolidated the opinions of various experts, we propose a research model consisting of two stages: trust-building factors and trust based on two reasons. First, prior research has proven the positive effect of trust on consequences; therefore, we emphasize the first two stages more. Second, in this research, we deem that a trust-building mechanism in different circumstances is much more important than the behavioral intentions; therefore, the factors could be relatively comprehensive. Therefore, we consider "antecedents of trust" and "trust" and develop appropriate hypotheses.

\section{Conceptual Framework and Hypotheses Development}

We choose seven trust factors as trust antecedents. First, the trustee-related factor is reputation. Second, the interaction factors are information quality, perceived similarity, reciprocity, shared value, satisfaction and SNS interaction. Here, the trustor-related factors, such as mood and disposition to trust, are not included in the conceptual framework because trust varies in personalized situations. These seven factors have been proved to have positive impacts on trust, and their concept and content are mutually exclusive, which reflects the trust generation mechanism more comprehensively.

Based on previous research, we propose our research model as shown in Figure 1 , and the hypothesis is as follows.

\subsection{Factors That Influence Social Network Trust}

\subsubsection{Information Quality and Trust}

Previous studies have illustrated how important the information quality is to the

\section{Factors}

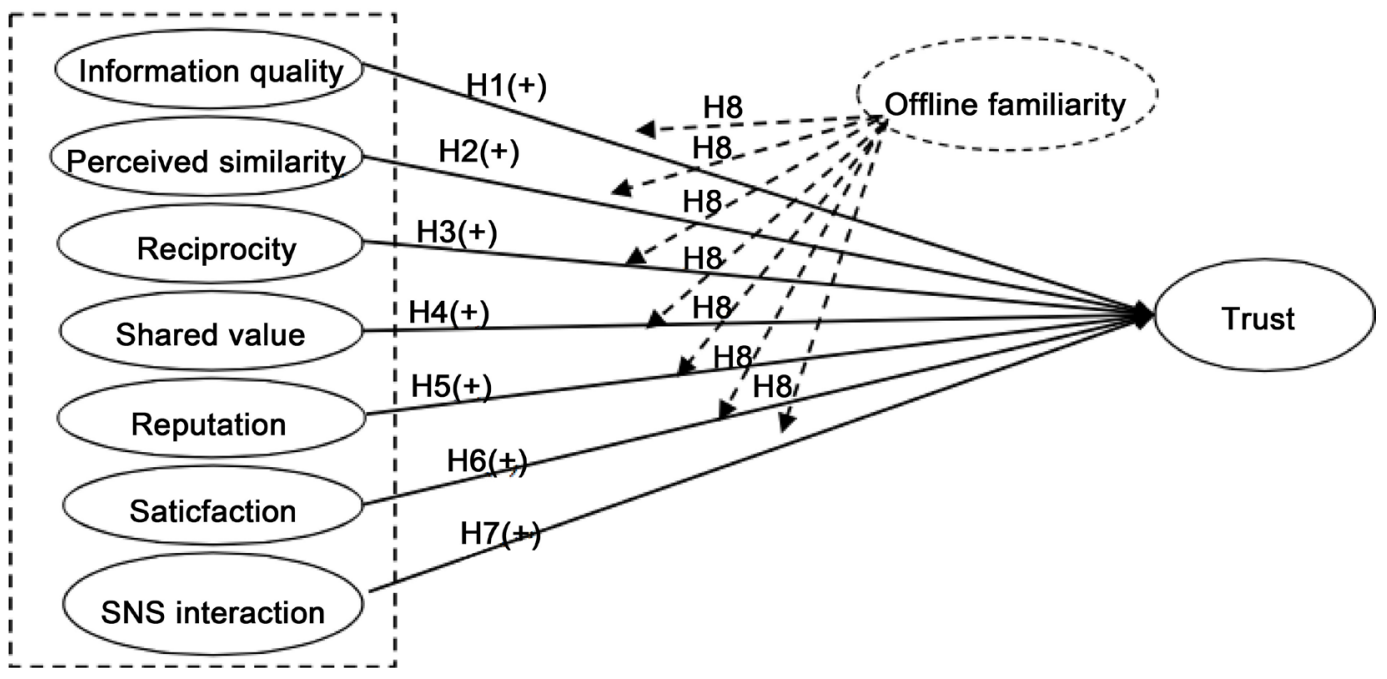

Figure 1. Research model. 
be free from error [31]; they are more likely to trust websites that contain accu trust between e-commerce traders. All customers expect that any website should rate, current, and complete information [32]. According to Liao, Palvia and Lin (2006), the content quality of an e-vendor's website (referring to usefulness, accuracy, and completeness of the information offered) will make the vendor appear more reliable and the customers believe that the relevant transaction is trustworthy [33]. Moreover, high quality information on websites helps to reduce the uncertainty and risk in transactions, which contributes to increasing online trust [25],

Social networks and virtual communities have created strong environments for user-generated content, and the content quality is crucial for the development of trust between members. Information quality refers to the extent to which a user views the information provided by another as current, accurate, relevant, useful, and comprehensive, which reflects an information provider's characteristics of competence, truthfulness and credibility; this engenders trusting beliefs in the information provider [34] [35]. Higher levels of information quality should be directly associated with higher levels of initial trust. Past research has identified information quality as an important trust-building mechanism in on-line interactions.

H1: Information quality has a positive association with social network trust.

\subsubsection{Perceived Similarity and Trust}

Perceived similarity means social similarities such as common characteristics the trustor perceives of the trustee including interests, values, experiences, and demographic traits (age, sex, occupation, and cultural background). Researchers have found the trust building mechanism exists in establishing a new trust relationship between two sufficiently similar users based on similarity [23] [26] [36] [37]. Walczuch, R. and H. Lundgren (2004) believe that people with a high level of perceived similarity tend to attract one another more; thus, members tend to be more influenced by the norms and values of similar members than dissimilar ones [29], contributing to the development of close relationships and trust. Moreover, the greater degree of similarity implies a higher similarity of background expectations and a greater level of shared understanding between members. Thus, similarity enables people to create a feeling of shared ethical and moral habits, and thus allows people to believe that other's behaviors are appropriate and ethical. Therefore, trust can be created [1] [38]. In a relational context, evidence drawn from the literature on social psychology has shown that relationship satisfaction is influenced by the similarity among individuals; the same relationship exists in the online environment. People are inclined to adopt recommendations from those who are more similar to them [23]. When people are grouped together in the same community, they tend to perceive each other in a positive manner, which enhances their trust belief [19]. In SNS and virtual communities, similar interests, values and experiences allow for trust building among members.

H2: Perceived similarity has a positive association with social network trust. 


\subsubsection{Reputation and Trust}

Reputation means that one assigns attributes to another person based on second-hand information regarding the person [14]. For example, an individual may believe that another individual has a good reputation because his/her friends or co-workers have said good things regarding that person. Therefore, people with good reputations are always categorized as trustworthy individuals. With a good reputation, another individual can develop trusting beliefs regarding that person without first-hand knowledge [14] [19]. We may wonder, how could this happen? On the one hand, reputation will reflect the characteristics of the individual worthy of trusting, such as professional competence or the other trusting beliefs: benevolence, honesty, and predictability in an SNS environment. A person may be perceived as a competent individual because she or he is a member of a competent group [19]. On the other hand, in an E-commerce environment, sellers will ensure their trust-worthy behaviors to maintain their customers, because repeated failures to fulfill customer intentions could eventually result in the depreciation of their reputation, and the customer will never return. Therefore, these second-hand information sources, such as feedback from friends or word-of-mouth comments from other customers, can also positively impact users' online trust [29]. Those who have no online shopping experience will rely on the seller's reputation.

H3: Reputation has a positive association with social network trust.

\subsubsection{Reciprocity and Trust}

Reciprocity in an online environment means that trustor and trustee meet the needs of mutual interest in the process of interaction. Here, we particularly refer to supportive responses, which mean responding compassionately to another person's distress to comfort others when he or she encounters difficulties. As common sense, if you want another's trust, you should show them you are supportive and helpful [11].

From the perspective of a responder, a supportive response will easily acquire emotional recognition. According to the most basic of socially accepted principles, responsiveness can indicate integrity, benevolence, cooperative intentions and respect [10]. This indication is due to the responders' intentions to cooperate with others, which will positively impact integrity and benevolence; affect-based trust naturally forms. Much research has demonstrated that the anonymous characteristic of online communication makes people more spiteful and more prepared to strike out. Therefore, normal performance and cooperative behavior online will help people build strong impressions in front of others, in contrast to the millions of malicious and assaulting messages [11]. In sum, when an individual exhibits characteristics of integrity and benevolence through supportive responses to other members in an SNS and builds tighter ties among them, that will promote trust.

From the perspective of a content provider, an individual who posts messages on SNSs most often expects a certain type of response. If an individual posts a message and there are no responses, trust in others will not develop [1]. If others 
respond quickly and often, it may be that they have the skills and competencies to be able to exchange accurate and helpful information, thereby building belief in their ability. In general, the major motivation for members to participate in VCs is to access useful information regarding friends or major issues [28]. The members who share their knowledge often expect a certain type of response from others in lieu of their contributions in the future [39]. In this view, knowledge contributors usually treat others' responsiveness as reciprocal benefits; this promotes a reciprocity exchange relationship, developing trust among members.

H4: Reciprocity has a positive association with social network trust.

\subsubsection{Shared Value and Trust}

Shared values are fundamental drivers of culture. Shared values refer to common social principles, norms, and goals that guide behavior patterns and cognitive perceptions of virtual community members [9], which connect types of individuals to a common system and enables members to similarly interpret the communication. In this very system, partners have common beliefs regarding what behaviors, goals, and policies are important or unimportant, appropriate or inappropriate, and right or wrong [27]. Everyone commits to take the appropriate actions to maintain their relationships and trust each other. Moreover, shared values lead to the construction of homogenous symbol systems and behavior logics that foster a sense of belonging and affiliation among members in an SNS [40], which leads to mutual understanding and trust because they facilitate interaction and communication within groups [41].

Morgan and Hunt (1994) indicate that it is easier for members to understand each other's beliefs and expectations when they have a similar sense of cultural values [42]; this eventually fosters trust. Having the same values helps members to understand better how they think and behave [41]. When individuals share the same values, they are apt to be kind to each other, and this encourages the production of trust. Therefore, we suggest that shared values are an important predictor of social trust whether online or offline.

H5: Shared values have a positive association with social network trust.

\subsubsection{Satisfaction and Trust}

Hellier et al. define customer satisfaction as "the overall level of customer pleasure and contentment resulting from the ability of the service to fulfill the customer's desires, expectations, and needs in relation to the service" [43]. Briefly, satisfaction is a positive affective state resulting from the appraisal of all aspects of the community services and interaction [9] [44]. In this research, we consider satisfaction to be the feelings of pleasure or disappointment resulting from the interaction process with other community members in social networks.

Thorngate noted that "If a response generated in an interaction is judged to be satisfactory, it will tend to be reproduced under subsequent, equivalent circumstances" [45]. As such, satisfaction experiences accumulate. Moreover, satisfaction is an important antecedent to helping behaviors. If members are satisfied with each other, they become more likely to have a caring attitude towards the 
other and show empathy or become more supportive [44]. For a period of time, satisfaction resulting from interactions tends to lead to the development of trust and continuous relationships. Zolfaghar and Aghaie (2012) conduct a prediction model in which the overall satisfaction in interactions performed between trustor and trustee has a critical effect on knowledge-based trust [37].

Generally, people who have had positive experiences with online purchasing will tend to trust online sellers [46]. In the same manner, members who have pleasant communication or interaction processes on social networks will ensure that others obtained a suitable level of honesty, benevolence and competence. Therefore, member satisfaction directly contributes to member trust. Community satisfaction is fundamental to the development of mutual trust between virtual community members.

H6: Satisfaction has a positive association with social network trust.

\subsubsection{SNS Interaction and Trust}

SNS interactions are associated with the level of closeness and communication frequency among the members on social networks. Through close social interaction, members can enhance the relationships between others [47]. Social interaction also help members involved in the process obtain the necessary information for a better understanding of each other, and then predict others' behaviors based on the information they obtain from this interactive process. Tsai and Ghoshal (1998) believed that frequent interaction makes the individual know the values, characteristics, principles of others. When members frequently interact, their relationship becomes more definite; in addition, the history of interactions allows individuals to perceive others' reliability and dependability [10]. In this regard, the better one knows another, the better one can trust what the other will do, because he or she can accurately predict how the other will respond in most situations; this finally fosters trust [37].

Members are able to improve the relationships among them through closer interaction with others; this means that trust is the product of repeated social interactions. From the perspective of social capital theory, social interactions strengthen network density and closure and thus promote trust in a person [1] [48]. Conversely, frequent interactions allow individuals to know one another; thus, they are more likely to perceive others as trustworthy [49]. Based on the arguments, we propose that SNS interaction will influence trust in members positively.

H7: SNS interaction has a positive association with social network trust.

\subsection{The Moderating Role of Offline Familiarity}

Offline familiarity is far different from online familiarity. The most fundamental difference is in the styles of cognition, whether one is known online or offline, namely, whether one knows a real individual in reality or a virtual one on SNS. Offline familiarity is an overall evaluation of the depth of understanding of others' thoughts, values, characters, and behaviors in real life as friends instead of on SNSs. 
Due to the growth of social networks, personal relationships are forming online as well as offline, and people can also make new friends and maintain relationships online, such that senders and receivers do not need to look at each other face-to-face in social networks such as Facebook or Twitter [16]. Consequently, there are two types of friends, who are distinguished by offline familiarity: friends who know each other online and offline, and friends who know each other online but not offline. Different types of friends depend on different reasons. Certain researchers believed the frequency of contact to be crucial in the formulation of online trust; [50] however, this occurs solely when people are not familiar with these friends offline. People need more SNS interaction or self-disclosure to know them. When people resure regarding behaviors or principles of offline friends, SNS interaction is not as important.

Traditionally, familiarity is the direct result of social interaction; people know SNS members who appeared on an SNS. Therefore, researchers believe that the level of familiarity is a key factor that causes differences in the degree of trust. Moreover, Jiménez and Martín (2010) find that culture familiarity with the very origin moderates the relationships between antecedents such as reputation, ethnocentrism, animosity and trust [51]. Therefore, in this research, we assume that the antecedents we noted above and trust is moderated by offline familiarity. And before that, there is no researchers take offline familiarity as a moderator in relationship between antecedents and online trust, making this paper different from predecessors' research.

H8: In SNS, offline familiarity will strengthen the relationship between antecedents of trust and social network trust.

\section{Research Methodology}

\subsection{Measurement Development}

In this research, there are two questionnaires for two situations: one for offline familiarity, in which respondents are familiar with members in an SNS offline; another for offline unfamiliarity. Offline familiarity is a dichotomous variable here rather than a continuous variable.

All the other constructs and the corresponding measure items are adapted from the previous literature to fit the context of this study. The questionnaire is composed of eight major constructs: SNS interaction, reciprocity, trust, information quality, shared value, reputation, perceived similarity and satisfaction.

China is a typical relational society, meaning that most of things people do is based on the relationship between one and the other. So in this research sampled users of Wei Bo which is the most popular SNS channel in China were chosen. Because the survey targets are Chinese, to improve the credibility and validity of the measurement tool, bilingual researchers have translated the items from English to Chinese and executed a cognitive interview to prevent them from destroying the item's original concept and meaning. All the items were measured in a structured format on a 7-point Likert-type scale ranging from 1 (strongly incompatible) to 7 (strongly compatible). 
Before the final study, we conducted a pretest over 10 samples to ensure that the question content, wording, sequence, format and layout, question difficulty, instructions, and the range of the scales (5-point vs. 7-point) were appropriate. After reviewing responses from the pretest, we made minor adjustments to refine the final version of the questionnaire. The survey items are in Table 1.

Table 1. Measurement Items.

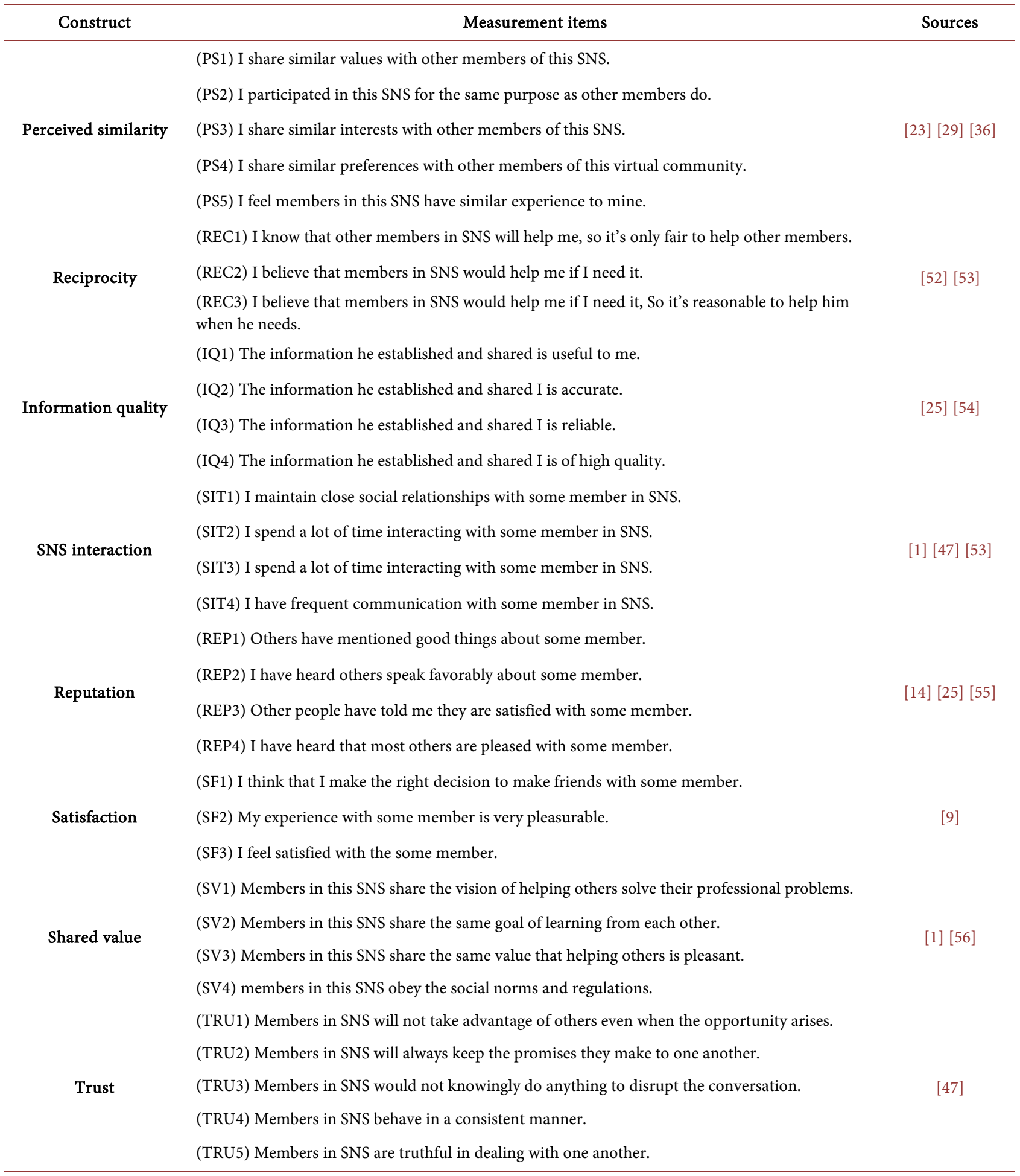




\subsection{Data Collection and Respondent Characteristics}

The survey population in this research is SNS users from China who actively use SNS, both on mobile devices and on PCs. Therefore, the SNS environment in China provides a suitable foundation for our studies. Responses were collected in two ways: paper questionnaires that filled with pens and online ones through PCs or cellphone. Finally, more than 600 people response the questionnaire and 598 is valid ones. The characteristics of survey respondents can be viewed in $\mathrm{Ta}$ ble 2.

\section{Data Analysis and Results}

\subsection{Reliability and Validity of the Measures}

Data analysis is composed of three primary phases. First, we performed an exploratory factor analysis (EFA) using the principal component method and a Varimax rotation using SPSS 21.0 to extract factors of the latent variables. Measurement items' factor loadings, eigenvalues, and variances were calculated, and eight factors were extracted. The results of EFA are shown in Table 3; it shows that the eigenvalues are all above 1.0 for each component, and extracted factors explain approximately $76.7 \%$ of the total variance.

Table 2. Demographics of survey respondents.

\begin{tabular}{|c|c|c|}
\hline \multicolumn{2}{|c|}{ Demographic variables $(N=598)$} & \multirow{2}{*}{$\begin{array}{c}N(\%) \\
293(49.0 \%)\end{array}$} \\
\hline Gender & Male & \\
\hline & Female & $305(51.0 \%)$ \\
\hline \multirow[t]{4}{*}{ Age } & Teenagers & $2(0.3 \%)$ \\
\hline & $20-25$ & $390(65.2 \%)$ \\
\hline & $26-30$ & $191(0.3 \%)$ \\
\hline & Above 30 & $15(2.5 \%)$ \\
\hline \multirow[t]{4}{*}{ Education } & High school or College & $57(9.5 \%)$ \\
\hline & University & $194(32.4 \%)$ \\
\hline & Graduate school & $301(50.3 \%)$ \\
\hline & Philosophy school & $46(7.7 \%)$ \\
\hline \multirow[t]{5}{*}{ SNS experience } & Less than half a year & $18(3.0 \%)$ \\
\hline & $0.5-1$ years & $30(5.0 \%)$ \\
\hline & $1-2$ years & $85(14.2 \%)$ \\
\hline & $2-3$ years & $108(18.1 \%)$ \\
\hline & Above 3 years & $357(59.7 \%)$ \\
\hline \multirow[t]{5}{*}{ Motivation to use SNS } & Entertainment and kill some boring time & $493(30.6 \%)$ \\
\hline & Get some useful knowledge or information & $486(30.2 \%)$ \\
\hline & Maintain good social relationships with friends & $421(26.1 \%)$ \\
\hline & Make new friends on social networks & $117(7.3 \%)$ \\
\hline & It's fashionable to use social networks & $94(5.8 \%)$ \\
\hline
\end{tabular}


Table 3. Results of exploratory factor analysis.

\begin{tabular}{|c|c|c|c|c|c|c|c|c|}
\hline \multirow{2}{*}{ Items } & \multicolumn{8}{|c|}{ Component } \\
\hline & 1 & 2 & 3 & 4 & 5 & 6 & 7 & 8 \\
\hline PS1 & 0.184 & 0.062 & 0.116 & 0.846 & 0.038 & 0.002 & -0.026 & 0.099 \\
\hline PS2 & 0.076 & 0.105 & 0.185 & 0.791 & 0.125 & 0.114 & 0.022 & 0.006 \\
\hline PS3 & 0.054 & 0.128 & 0.137 & 0.697 & -0.005 & 0.172 & 0.091 & 0.193 \\
\hline PS4 & 0.105 & -0.042 & 0.065 & 0.847 & 0.114 & -0.007 & -0.061 & 0.089 \\
\hline PS5 & -0.074 & 0.190 & -0.158 & 0.582 & 0.056 & 0.022 & 0.206 & 0.036 \\
\hline SNSI1 & 0.023 & 0.767 & 0.132 & 0.123 & 0.016 & 0.176 & 0.341 & 0.130 \\
\hline SNSI2 & 0.075 & 0.874 & 0.041 & 0.166 & 0.047 & -0.127 & 0.085 & 0.061 \\
\hline SNSI3 & 0.111 & 0.822 & 0.206 & -0.003 & 0.018 & 0.059 & 0.247 & 0.079 \\
\hline SNSI4 & 0.037 & 0.875 & 0.095 & 0.135 & -0.041 & -0.014 & 0.142 & 0.156 \\
\hline SF1 & 0.124 & 0.245 & 0.183 & 0.109 & 0.136 & 0.113 & 0.104 & 0.789 \\
\hline SF2 & 0.200 & 0.213 & 0.234 & 0.191 & 0.126 & 0.115 & 0.152 & 0.774 \\
\hline SF3 & 0.194 & 0.016 & 0.202 & 0.158 & 0.236 & 0.192 & 0.107 & 0.749 \\
\hline IQ1 & 0.266 & -0.075 & 0.052 & 0.133 & 0.603 & 0.197 & -0.040 & 0.223 \\
\hline IQ2 & 0.095 & 0.041 & 0.159 & 0.040 & 0.849 & 0.091 & 0.042 & 0.075 \\
\hline IQ3 & 0.153 & 0.060 & 0.225 & 0.093 & 0.846 & 0.131 & 0.106 & 0.116 \\
\hline IQ4 & 0.150 & -0.017 & 0.301 & 0.092 & 0.731 & 0.180 & 0.181 & 0.094 \\
\hline REC1 & 0.126 & 0.297 & 0.249 & 0.051 & 0.093 & 0.205 & 0.817 & 0.130 \\
\hline REC2 & 0.128 & 0.295 & 0.186 & 0.064 & 0.135 & 0.173 & 0.860 & 0.112 \\
\hline REC3 & 0.152 & 0.310 & 0.245 & 0.076 & 0.078 & 0.130 & 0.814 & 0.135 \\
\hline REP1 & 0.813 & 0.118 & 0.182 & 0.060 & 0.174 & 0.122 & 0.052 & 0.167 \\
\hline REP2 & 0.875 & 0.055 & 0.176 & 0.129 & 0.086 & 0.166 & 0.064 & 0.124 \\
\hline REP3 & 0.820 & 0.036 & 0.193 & 0.101 & 0.134 & 0.144 & 0.182 & 0.101 \\
\hline REP4 & 0.731 & 0.067 & 0.264 & 0.075 & 0.274 & 0.173 & 0.084 & 0.114 \\
\hline SV1 & 0.285 & -0.009 & 0.158 & 0.113 & 0.252 & 0.653 & 0.182 & 0.048 \\
\hline SV2 & 0.029 & 0.000 & 0.042 & 0.141 & 0.243 & 0.829 & 0.082 & 0.141 \\
\hline SV3 & 0.187 & 0.046 & 0.158 & 0.111 & 0.111 & 0.834 & 0.157 & 0.156 \\
\hline SV4 & 0.203 & 0.017 & 0.379 & -0.069 & 0.027 & 0.705 & 0.093 & 0.074 \\
\hline TR1 & 0.257 & 0.138 & 0.695 & 0.050 & 0.248 & 0.211 & 0.178 & 0.155 \\
\hline TR2 & 0.267 & 0.089 & 0.717 & 0.123 & 0.154 & 0.172 & 0.215 & 0.302 \\
\hline TR3 & 0.203 & 0.152 & 0.685 & 0.168 & 0.239 & 0.184 & 0.174 & 0.201 \\
\hline TR4 & 0.241 & 0.244 & 0.618 & 0.141 & 0.324 & 0.237 & 0.158 & 0.174 \\
\hline TR5 & 0.319 & 0.199 & 0.666 & 0.129 & 0.305 & 0.147 & 0.265 & 0.138 \\
\hline Eigenvalue & 11.7 & 3.5 & 2.7 & 1.8 & 1.6 & 1.3 & 1.1 & 1.0 \\
\hline Variance (\%) & 36.5 & 10.8 & 8.3 & 5.5 & 5.1 & 4.1 & 3.4 & 3.0 \\
\hline $\begin{array}{c}\text { Cumulative } \\
\text { variance (\%) }\end{array}$ & 36.5 & 47.4 & 55.7 & 61.2 & 66.3 & 70.4 & 73.7 & 76.7 \\
\hline
\end{tabular}


Next, confirmatory factor analysis (CFA) was conducted to determine whether they possessed appropriate properties to represent respective constructs, and the result of cross-loading is summarized in Table 4 . Then, we tested the validity and reliability of the measures. Convergent validity and reliability was measured

Table 4. Results of confirmatory factor analysis (cross-loading).

\begin{tabular}{|c|c|c|c|c|c|c|c|c|}
\hline & 1 & 2 & 3 & 4 & 5 & 6 & 7 & 8 \\
\hline IQ1 & 0.019 & 0.154 & 0.400 & 0.702 & 0.373 & 0.403 & 0.238 & 0.360 \\
\hline IQ2 & 0.088 & 0.223 & 0.448 & 0.847 & 0.307 & 0.336 & 0.177 & 0.314 \\
\hline IQ3 & 0.150 & 0.317 & 0.561 & 0.915 & 0.400 & 0.428 & 0.251 & 0.416 \\
\hline IQ4 & 0.121 & 0.352 & 0.596 & 0.869 & 0.440 & 0.431 & 0.236 & 0.395 \\
\hline PS1 & 0.197 & 0.147 & 0.294 & 0.213 & 0.174 & 0.282 & 0.869 & 0.307 \\
\hline PS2 & 0.234 & 0.203 & 0.349 & 0.269 & 0.255 & 0.252 & 0.856 & 0.289 \\
\hline PS3 & 0.289 & 0.272 & 0.338 & 0.210 & 0.271 & 0.249 & 0.800 & 0.373 \\
\hline PS4 & 0.079 & 0.061 & 0.238 & 0.227 & 0.145 & 0.199 & 0.820 & 0.259 \\
\hline PS5 & 0.255 & 0.189 & 0.109 & 0.073 & 0.071 & 0.030 & 0.503 & 0.159 \\
\hline REC1 & 0.557 & 0.957 & 0.576 & 0.308 & 0.440 & 0.359 & 0.206 & 0.417 \\
\hline REC2 & 0.555 & 0.971 & 0.540 & 0.337 & 0.414 & 0.357 & 0.213 & 0.403 \\
\hline REC3 & 0.570 & 0.952 & 0.571 & 0.291 & 0.384 & 0.371 & 0.227 & 0.426 \\
\hline REP1 & 0.233 & 0.316 & 0.549 & 0.415 & 0.401 & 0.880 & 0.220 & 0.426 \\
\hline REP2 & 0.193 & 0.306 & 0.545 & 0.365 & 0.447 & 0.919 & 0.276 & 0.412 \\
\hline REP3 & 0.200 & 0.380 & 0.558 & 0.404 & 0.425 & 0.898 & 0.261 & 0.397 \\
\hline REP4 & 0.210 & 0.344 & 0.604 & 0.513 & 0.455 & 0.870 & 0.256 & 0.428 \\
\hline SF1 & 0.388 & 0.375 & 0.508 & 0.351 & 0.333 & 0.360 & 0.282 & 0.871 \\
\hline SF2 & 0.403 & 0.438 & 0.584 & 0.378 & 0.374 & 0.439 & 0.368 & 0.919 \\
\hline SF3 & 0.214 & 0.337 & 0.541 & 0.457 & 0.426 & 0.440 & 0.326 & 0.874 \\
\hline SNSI1 & 0.893 & 0.616 & 0.419 & 0.156 & 0.266 & 0.223 & 0.273 & 0.377 \\
\hline SNSI2 & 0.851 & 0.387 & 0.265 & 0.070 & -0.017 & 0.159 & 0.261 & 0.263 \\
\hline SNSI3 & 0.906 & 0.548 & 0.424 & 0.133 & 0.179 & 0.261 & 0.167 & 0.335 \\
\hline SNSI4 & 0.892 & 0.466 & 0.332 & 0.042 & 0.085 & 0.162 & 0.253 & 0.343 \\
\hline SV1 & 0.126 & 0.390 & 0.501 & 0.439 & 0.820 & 0.470 & 0.243 & 0.360 \\
\hline SV2 & 0.091 & 0.297 & 0.388 & 0.408 & 0.820 & 0.288 & 0.257 & 0.333 \\
\hline SV3 & 0.181 & 0.403 & 0.498 & 0.377 & 0.902 & 0.426 & 0.259 & 0.407 \\
\hline SV4 & 0.145 & 0.342 & 0.513 & 0.319 & 0.814 & 0.418 & 0.111 & 0.327 \\
\hline TR1 & 0.321 & 0.477 & 0.855 & 0.518 & 0.510 & 0.542 & 0.242 & 0.499 \\
\hline TR2 & 0.325 & 0.517 & 0.876 & 0.483 & 0.492 & 0.557 & 0.322 & 0.588 \\
\hline TR3 & 0.358 & 0.483 & 0.851 & 0.512 & 0.472 & 0.509 & 0.353 & 0.519 \\
\hline TR4 & 0.406 & 0.499 & 0.867 & 0.563 & 0.524 & 0.549 & 0.343 & 0.545 \\
\hline TR5 & 0.406 & 0.573 & 0.903 & 0.573 & 0.491 & 0.599 & 0.323 & 0.523 \\
\hline
\end{tabular}

Base: 1 SNS interaction, 2 reciprocity, 3 trust, 4 information quality, 5 shared value, 6 reputation, 7 perceived similarity, 8 satisfaction. 
by examining the standardized path loadings and the Cronbach's alpha of the items; they all exceeded the minimum acceptable value of 0.7 . Reliability of the scale items was examined using composite reliability (CR) and AVE values, and the thresholds of the two indices were set at 0.7 and 0.5 [57] [58]. In this study, the CR scores of every construct (ranging from 0.88 to 0.97 ) were significantly higher than 0.70 , which suggests that convergent validity is acceptable. The results are summarized in Table 5.

Table 5. Results of convergent validity and reliability.

\begin{tabular}{|c|c|c|c|c|c|c|}
\hline Variable & Item & Std. loading & $t$-value & AVE & $\mathrm{CR}$ & $\alpha$ \\
\hline \multirow[t]{4}{*}{1} & IQ1 & 0.702 & 20.11 & 0.700625 & 0.90 & 0.855421 \\
\hline & IQ2 & 0.847 & 54.56 & & & \\
\hline & IQ3 & 0.915 & 128.74 & & & \\
\hline & IQ4 & 0.869 & 64.93 & & & \\
\hline \multirow[t]{5}{*}{2} & PS1 & 0.869 & 50.59 & 0.610691 & 0.88 & 0.8381 \\
\hline & PS2 & 0.856 & 58.01 & & & \\
\hline & PS3 & 0.800 & 44.74 & & & \\
\hline & PS4 & 0.820 & 40.61 & & & \\
\hline & PS5 & 0.503 & 10.98 & & & \\
\hline \multirow[t]{3}{*}{3} & REC1 & 0.957 & 214.56 & 0.921696 & 0.97 & 0.957494 \\
\hline & REC2 & 0.971 & 285.23 & & & \\
\hline & REC3 & 0.952 & 165.08 & & & \\
\hline \multirow[t]{4}{*}{4} & REP1 & 0.880 & 77.68 & 0.795838 & 0.94 & 0.91439 \\
\hline & REP2 & 0.919 & 131.24 & & & \\
\hline & REP3 & 0.898 & 96.32 & & & \\
\hline & REP4 & 0.870 & 79.84 & & & \\
\hline \multirow[t]{3}{*}{5} & SF1 & 0.871 & 68.76 & 0.788545 & 0.92 & 0.865771 \\
\hline & SF2 & 0.919 & 111.70 & & & \\
\hline & SF3 & 0.874 & 76.53 & & & \\
\hline \multirow[t]{4}{*}{6} & SNSI1 & 0.893 & 86.58 & 0.784465 & 0.94 & 0.909974 \\
\hline & SNSI2 & 0.851 & 49.36 & & & \\
\hline & SNSI3 & 0.906 & 125.35 & & & \\
\hline & SNSI4 & 0.892 & 64.70 & & & \\
\hline \multirow[t]{4}{*}{7} & SV1 & 0.820 & 44.93 & 0.705562 & 0.91 & 0.860781 \\
\hline & SV2 & 0.820 & 46.58 & & & \\
\hline & SV3 & 0.902 & 100.95 & & & \\
\hline & SV4 & 0.814 & 58.86 & & & \\
\hline \multirow[t]{5}{*}{8} & TR1 & 0.855 & 50.29 & 0.758192 & 0.94 & 0.920165 \\
\hline & TR2 & 0.876 & 86.59 & & & \\
\hline & TR3 & 0.851 & 55.94 & & & \\
\hline & TR4 & 0.867 & 70.66 & & & \\
\hline & TR5 & 0.903 & 110.40 & & & \\
\hline
\end{tabular}

Base: 1 information quality, 2 perceived similarity, 3 reciprocity, 4 reputation, 5 satisfaction, 6 SNS interaction, 7 shared value, 8 trust (bold number shows square roots of AVE for that construct, ${ }^{* *}: p<0.01$ ). 
Table 6. Correlations between latent variables.

\begin{tabular}{cccccccccc}
\hline Variable & Mean & 1 & 2 & 3 & 4 & 5 & 6 & 7 & 8 \\
\hline 1 & 3.99 & 0.886 & & & & & & & \\
2 & 4.07 & 0.584 & 0.960 & & & & & & \\
3 & 3.99 & 0.418 & 0.586 & 0.871 & & & & & \\
4 & 3.91 & 0.120 & 0.325 & 0.609 & 0.837 & & & & \\
5 & 4.03 & 0.165 & 0.430 & 0.572 & 0.457 & 0.840 & & & \\
6 & 3.76 & 0.235 & 0.378 & 0.634 & 0.478 & 0.485 & 0.892 & & \\
7 & 4.21 & 0.264 & 0.224 & 0.364 & 0.269 & 0.255 & 0.284 & 0.781 & \\
8 & 4.23 & 0.378 & 0.433 & 0.614 & 0.445 & 0.426 & 0.466 & 0.368 & 0.888 \\
\hline
\end{tabular}

Base: 1 information quality, 2 perceived similarity, 3 reciprocity, 4 reputation, 5 satisfaction, 6 SNS interaction, 7 shared value, 8 trust (bold number shows square roots of AVE for that construct, ${ }^{* *}: p<0.01$ ).

Finally, to satisfy the requirements regarding discriminant validity, all the square roots of AVE values should exceed the correlation between each latent variable and other latent variables in the model; furthermore, all the correlation values of latent variables need to be less than 0.7. As we can observe in Table 6, we can conclude that the discriminant validity of constructs in the model is obtained.

\subsection{Main Effects}

Once the measurement was adequate, we tested the hypotheses by reviewing the parameters in the structural model. The purpose of this research was to test how the factors affect social network trust in SNS use and which factors have the greater impact on social network trust. In addition, we want to know the moderating effect of offline familiarity. Thus, to test the hypotheses, this study performed structural equation modeling (SEM) analysis to examine the main effects with the basic model, and then performed a multi-group analysis to test the moderating role of offline familiarity. The explanation power and predictive relevance of the structural models that examine the effect of the seven factors on social network trust is measured by $R$-squared $\left(R^{2}\right)$, which is $68.3 \%$; this shows that our developed path model has high explanatory power and high predictive relevance.

We also conducted a global fit measure (GoF) for PLS path modeling, which is defined as the geometric mean of the average communality and average $R^{2}$. In accordance with the guidelines of Wetzels et al. [59], we estimated the GoF values, which may serve as cut-off values for the global validation of PLS models. In this study, we obtained a GoF value of 0.7195 for the complete (main effects) model, which exceeds the cut-off value of 0.36 for large effect sizes of $R^{2}$. As such, the result allows us to conclude that our model has better explaining power in comparison with the baseline values

$\left(\mathrm{GoF}_{\text {small }}=0.1, \mathrm{GoF}_{\text {medium }}=0.25, \mathrm{GoF}_{\text {large }}=0.36\right)$. The result also provides adequate support to validate the PLS model globally; the suitability of structure 


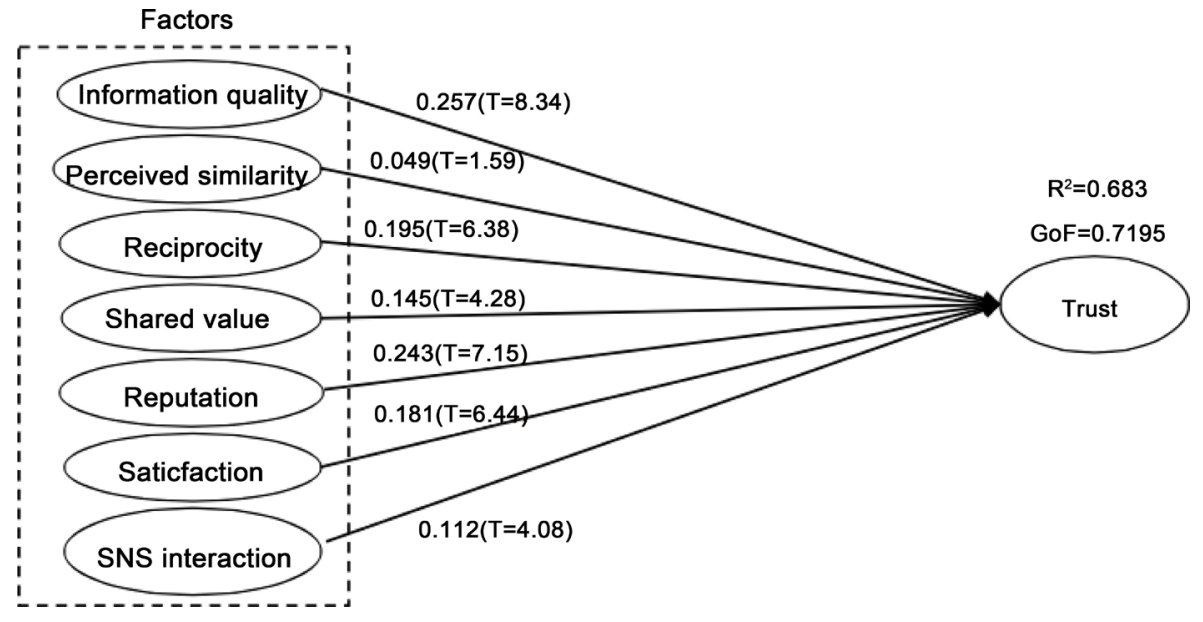

Figure 2. Main effects.

model is very high [59] [60].

$$
\mathrm{GoF}=\sqrt{\overline{\mathrm{AVE}} * \overline{R^{2}}}=0.7195 .
$$

Figure 2 shows the results of the main effects. The findings show that $H 1, H 3$, $H 4, H 5, H 6$ and $H 7$ were supported, whereas $H 2$ was not supported. Among the seven factors of trust in social network, reputation (beta $=0.243, t=7.15$ ), SNS interaction (beta $=0.112, t=4.08$ ), satisfaction (beta $=0.181, t=6.44$ ), reciprocity (beta $=0.195, t=6.38$ ), information quality (beta $=0.257, t=8.34$ ) and shared value (beta $=0.145, t=4.28$ ) were found to be positively associated with social network trust; conversely, perceived similarity (beta $=0.049, t=1.59$ ) had no significant impact on social network trust. These findings suggest that information quality and reputation are the main factors.

\subsection{Moderating Effects}

We analyzed the moderating effect by dividing the samples into two groups, familiar group and unfamiliar group. To investigate whether there is a difference for the moderating effects between the two groups, we used the Henseler (2007) approach to test the group differences, called Multi-Group Analysis (MGA) [61], which does not rely on any distributional assumptions; its principle is as follows.

Initially, the subsamples are exposed to separate bootstrap analyses, and the bootstrap outcomes serve as a basis for testing the potential group differences. Given two subsamples with different parameter estimates $\tilde{\theta}^{(1)}$ and $\tilde{\theta}^{(2)}$, groups can be indexed, without any loss of generality, so that $\tilde{\theta}^{(1)}>\tilde{\theta}^{(2)}$, to assess the significance of a group effect, the conditional probability $P$ $\left(\theta^{(1)} \leq \theta^{(2)} \mid \tilde{\theta}^{(1)}, \tilde{\theta}^{(2)}, \operatorname{CDF}\left(\theta^{(1)}\right), \operatorname{CDF}\left(\theta^{(2)}\right)\right)$ must be determined on the basis of the group-specific parameter estimates, $\tilde{\theta}^{(g)}(g \in\{1,2\})$ and the empirical cumulative distribution functions ( $\mathrm{CDFs}$ ).

In an initial step, the centered bootstrap estimates $\tilde{\theta}_{i}^{(g)^{*}}$ must be computed as follows:

$$
\tilde{\theta}_{i}^{(g)^{\bar{*}}}=\tilde{\theta}_{i}^{(g)^{*}}-\frac{1}{B} \sum_{I=1}^{B} \tilde{\theta}_{i}^{(g)^{*}}+\tilde{\theta}^{(g)}
$$


where $\tilde{\theta}_{i}^{(g)^{*}}$ represents the bootstrap estimate in group $g(g \in\{1,2\})$ and bootstrap sample $i(i \in\{1, \cdots, B\})$. By using the Heaviside step function, $H\left(x^{*}\right)$ is as defined by

$$
H\left(x^{*}\right)=\frac{1+\operatorname{sgn}\left(x^{*}\right)}{2}
$$

and the bootstrap estimates are discrete manifestations of the CDFs; the conditional probability is computed as follows:

$$
p\left(\theta^{(1)} \leq \theta^{(2)} \mid \tilde{\theta}^{(1)}, \tilde{\theta}^{(2)}, \operatorname{CDF}\left(\theta^{(1)}\right), \operatorname{CDF}\left(\theta^{(2)}\right)\right)=\frac{1}{B^{2}} \sum_{i=1}^{B} \sum_{j=1}^{B} H\left(\tilde{\theta}_{j}^{(2)^{\bar{x}}}-\tilde{\theta}_{j}^{(1)^{\bar{x}}}\right) .
$$

(Base $B=5000, \theta^{(1)}$ and $\theta^{(2)}$ represents the path coefficients for two groups.)

The significance of a moderator can be confirmed if $p$ is significant. To test this statistically, we conducted structural model analysis and bootstrap analysis using PLS bootstrapping for subgroups of the sample separately to observe whether the difference of path coefficients is significant and to decide whether the requirements for the group test (every sub model had acceptable fit values and no significant measurement invariance, for the familiar group GOF $=0.713$, $R^{2}=0.724$, and unfamiliar group GOF $=0.751, R^{2}=0.720$ ) were met.

Table 7 summarizes the result; it shows that the difference of moderating effects for the two subgroups (familiar and unfamiliar) is statistically significant in all four paths. Offline familiarity has a moderating effect over the relation between information quality and social network trust $(T=7.29)$, which means that the more familiar someone was offline, the less the person relied on the information quality provided over a period of time. Moreover, offline familiarity was also found to moderate the relation between reciprocity, shared value, reputation and social network trust $(T=7.94,2.62,2.20)$. We, therefore, argue that when a person becomes familiar with others in real life, that person becomes increasingly dependent on reciprocity ( beta $_{\text {fsmiliar }}=0.446$, beta unfamilar $=0.006$ ) and

Table 7. Comparison testing results between subgroups for offline familiarity.

\begin{tabular}{ccccccc}
\hline \multirow{2}{*}{ Path } & \multicolumn{2}{c}{ Familiar $(N=304)$} & \multicolumn{2}{c}{ Unfamiliar $(N=294)$} & \multirow{2}{*}{$t$-value } & Result \\
\cline { 2 - 5 } & Coefficient & S.E. & Coefficient & S.E. & & \\
\hline IQ $\rightarrow$ TRU & $0.106^{* *}$ & 0.042 & $0.432^{* * *}$ & 0.044 & 7.29 & Significantly weaken \\
PS $\rightarrow$ TRU & $0.064^{\text {n.s. }}$ & 0.033 & $0.096^{* *}$ & 0.047 & 1.11 & Not Significant \\
REC $\rightarrow$ TRU & $0.446^{* * *}$ & 0.042 & $0.006^{\text {n.s. }}$ & 0.035 & 7.94 & Significantly strengthen \\
SV $\rightarrow$ TRU & $0.059^{\text {n.s. }}$ & 0.046 & $0.208^{* * *}$ & 0.042 & 2.62 & Significantly weaken \\
REP $\rightarrow$ TRU & $0.279^{* * *}$ & 0.036 & $0.157^{* * *}$ & 0.054 & 2.20 & Significantly strengthen \\
SF $\rightarrow$ TRU & $0.144^{* * *}$ & 0.041 & $0.196^{* * *}$ & 0.042 & 1.30 & Not significant \\
SSNI $\rightarrow$ TRU & $0.014^{\text {n.s. }}$ & 0.036 & $0.055^{\text {n.s. }}$ & 0.037 & 1.25 & Not significant \\
\hline
\end{tabular}

Base: IQ (information quality), PS (perceived similarity), REC (reciprocity), REP (reputation), SF (satisfaction), SV (shared value), SSNI (SNS interaction), TRU (trust); n.s. = not significant; ${ }^{*} p<0.1$ (estimated by 5000 bootstraps "social network trust"; two-tailed t-test); ${ }^{* *} p<0.05$ (estimated by 5000 bootstraps "social network trust"; two-tailed t-test); ${ }^{* *} p<0.01$ (estimated by 5000 bootstraps "social network trust"; two-tailed t-test). 
reputation ( beta $_{\text {fsmiliar }}=0.279$, beta ${ }_{\text {unfamilar }}=0.157$ ) to decide when to trust them in social networks. The other perspective, shared value

${\text { ( } \text { beta }_{\text {fsmiliar }}=0.059 \text {, beta }}_{\text {unfamilar }}=0.208$ ) and information quality

( beta $_{\text {fsmiliar }}=0.106$, beta unfamilar $=0.432$ ) has more significant impact on social network trust.

\section{Discussion}

In this research, we proposed a theoretical model to examine trust among members of SNSs, how the antecedents of trust affect it and how offline familiarity moderates the relation between them. Based on data collected from members of "Wei Bo" in China, one of the most popular SNS in China, we find how trust building mechanisms work in SNS in different contexts of familiarity and differences. Next, we will summarize the important findings as follows.

First, we found that, among the seven antecedents of social network trust, all the factors except perceived similarity were found to positively influence social network trust, which suggests that members consider a relatively wide variety of perceptions and observations when developing their trust in SNS.

Perceived similarity does not positively affect trust. The result is inconsistent with previous studies, which have found that perceived similarity has a positive impact on virtual community trust [23]. VCs are completely anonymous; members must communicate with others to exchange information and learn about others to know whether a person is similar to him or her. Similarity is based on dense communication in VCs, which promotes trust generation. Although not in SNS, individuals can learn about members via different channels such as the comments of others or label information in the semi-real-name system without sufficient interaction, which make perceived similarity less important in trust generation.

As expected, information quality positively relates to trust, which is consistent with the findings in several research studies [7] [25] [35] [62]. This finding reveals that this user-generated content (UGC) is critical to demonstrate personal values and satisfy the social, entertainment, information acquisition, and skilllearning needs of other members. Helpful information makes trust generation easier. This study also shows that shared values have significant influence on trust. This finding is in accordance with prior studies [1] [28], which indicate that developing shared values and goals is a strong motivator for the establishment of trust in SNSs. The results also report the significant relation between SNS interaction and trust, which is similar to the results of past studies [19] [47] [63]. SNS interaction is the overall evaluation of the closeness of the relationship and interaction frequency between members after interaction on SNS. Social interaction will surely increase the density and depth of communication exchanges. The positive influence is proved. Moreover, reputation also has a strong direct influence on trust, which is also proved by scholars [19] [29]. Reputation means strong evaluations of professional competence and friendly behavior learned indirectly through other people. A high reputation implies a high level of trust. In 
addition, reciprocity is also found to be positively related to trust, as observed in several research studies [1] [10] [11]. Reciprocity means perceived positive response, helpful behaviors or returns that can be achieved in the future when members maintain a stable relationship with others. This type of behavior by a member will gain recognition in terms of other members' affection and cognition. Finally, satisfaction positively affects trust, which is consistent with the findings of previous literature [9] [17] [53]. In this research, satisfaction means the perception of pleasure or disappointment that occurred when or after members interact with each other. Satisfaction is an affection-based factor, and people will gain emotional recognition though it. Satisfaction is an important antecedent factor affecting trust formation in SNS. Manika and Papagiannidis have found that specific consumer and message-related factors, during and after exposure to a CEO YouTube apology could affect customers' satisfaction with the company after a service failure incident. They suggest that managers could invest time and effort by working closely with public relations agencies aiming to devise specific communication plans for different service failure scenarios [64].

Second, our findings show that offline familiarity is a relevant moderator in the context of the proposed model, moderating the relation between information quality, reciprocity, reputation, shared value and social network trust.

As offline familiarity increases, the effect of reciprocity in social network trust increases. Members who are familiar with each other will more likely ensure altruism occurs (0.446) to an extent. Conversely, the uncertainty of reciprocal behavior between unfamiliar online friends weakens the importance of reciprocity as an antecedent in the role of trust (0.006). Information quality is proven to be important in both situations; path coefficients are 0.106 for high offline familiarity, and 0.432 for a low level. This finding reveals the important role of the exchange within a social network; particularly, when people are not familiar, this would be the sole means to know others without direct interaction. Similarly, reputation is also critical in both; it is 0.279 when familiar with others and slightly higher for the opposite. In comparison, members more seriously regard reputation for familiar individuals much more worthy of trust. The effect of shared value on trust is also significantly different in the two situations, with 0.208 for a low level of offline familiarity and not significant for a high level. We believe that a trust relationship between close friends is mainly maintained by emotional intensity and intimacy; shared values can be a secondary factor.

\section{Conclusion}

The academic and practical value is expected to be fulfilled by the findings discussed above. Concisely, results concerning the main effect of six antecedents and moderating effect of offline familiarity have been revealed. In this proposal, we propose utilizing Chinese SNS users as the sample that is more meaningful because China is a typical relational society. Offline familiarity is innovatively introduced to distinguish interpersonal relationship tie strength: strong ties and weak ties, which previous research distinguishes with seven dimensions: emo- 
tional intensity, intimacy, sustainability, interaction frequency, close architecture, spiritual support and social disparities. Information quality develops trust in both kinds of tie strength, which offers implications for the direction of the improvements of SNS marketing; managers should make the information they issue more valuable. Besides, trust agents who are the key nodes connecting to different groups of members and communicating with them should be found to guide the positive public opinion and develop the brand influence for enterprises.

\section{Limitations and Future Research}

As discussed above, this study has interesting implications; however, there are limitations. Firstly, in regards to data collection, we collected respondents through convenience sampling. The problems are as follows. First, the data collection was performed in a particular country, China, and with a specific SNS service, Wei Bo. Second, the education distribution of samples mainly concentrated on undergraduates and above. These two limitations mean that our results cannot be generalized. Thus, in future studies, we should expand the scope of the sample and adopt a systematizing sampling strategy that considers region, age and education level. It is necessary to consider users from diverse cultures, multiple services, ages, education levels, and genders to include respondents with more diverse demographic attributes, making the conclusions more general.

Secondly, another limitation is the fact that the model in this study is not perfect for two reasons. First, the independent variables may have a more complex relation. We suppose that independent variables have no correlation, which means one would not affect another. However, we interpret the variables expression as independent in this research and follow the previous research model. Second, we have not found the critical antecedents of trust although seven independent variables, which have explained $78 \%$ of trust, already exist; next, we will focus our efforts on determining the influence of other factors, such as self-disclosure or perceived expertise.

Thirdly, taking offline familiarity as a distinction between strong and weak ties in SNS is a relatively rough way, which means the moderator has the limitation. When we get familiar with someone in real life, there is the strong tie. To the opposite, the weak tie exists. There are exceptions: people who show more self-disclosure behavior, have good reputation or interact with others more frequently can be strong ties with others although they have never met each other. In the future, exploring the criteria for the classification of strong and weak ties can be the interesting direction, such as emotional intensity, intimacy, interaction frequency and mental support. We leave these opportunities for future research.

\section{References}

[1] Hsu, M., Chang, C. and Yen, C. (2011) Exploring the Antecedents of Trust in Virtual Communities. Behaviour \& Information Technology, 30, 587-601.

https://doi.org/10.1080/0144929X.2010.549513

[2] Deutsch, M. (1958) Trust and Suspicion. Journal of Conflict Resolution, 2, 265-279. 
https://doi.org/10.1177/002200275800200401

[3] Rotter, J.B. (1967) A New Scale for the Measurement of Interpersonal Trust. Journal of Personality, 35, 651-665. https://doi.org/10.1111/j.1467-6494.1967.tb01454.x

[4] Luhmann, N., Davis, H., Raffan, J. and Rooney, K. (1979) Trust; and, Power: Two Works by Niklas Luhmann. Wiley, Chichester.

[5] Mayer, R.C., Davis, J.H. and Schoorman, F.D. (1995) An Integrative Model of Organizational Trust. Academy of Management Review, 20, 709-734.

[6] Corritore, C.L., Kracher, B. and Wiedenbeck, S. (2003) On-Line Trust: Concepts, Evolving Themes, a Model. International Journal of Human-Computer Studies, 58, 737-758.

[7] Beldad, A., De Jong, M. and Steehouder, M. (2010) How Shall I Trust the Faceless and the Intangible? A Literature Review on the Antecedents of Online Trust. Computers in Human Behavior, 26, 857-869.

[8] McKnight, D.H. and Chervany, N.L. (2001) Conceptualizing Trust: A Typology and E-Commerce Customer Relationships Model. Proceedings of the 34th Annual Hawaii International Conference on System Sciences, Maui, HI, 6 January 2001, 10. https://doi.org/10.1109/hicss.2001.927053

[9] Wu, J., Chen, Y. and Chung, Y. (2010) Trust Factors Influencing Virtual Community Members: A Study of Transaction Communities. Journal of Business Research, 63, 1025-1032.

[10] Ridings, C.M., Gefen, D. and Arinze, B. (2002) Some Antecedents and Effects of Trust in Virtual Communities. The Journal of Strategic Information Systems, 11, 271-295.

[11] Feng, J., Lazar, J. and Preece, J. (2004) Empathy and Online Interpersonal Trust: A Fragile Relationship. Behaviour \& Information Technology, 23, 97-106. https://doi.org/10.1080/01449290310001659240

[12] Moorman, C., Deshpande, R. and Zaltman, G. (1993) Factors Affecting Trust in Market Research Relationships. Journal of Marketing, 57, 81-101. https://doi.org/10.2307/1252059

[13] McKnight, D.H., Choudhury, V. and Kacmar, C. (2002) The Impact of Initial Consumer Trust on Intentions to Transact with a Web Site: A Trust Building Model. The Journal of Strategic Information Systems, 11, 297-323.

[14] Lankton, N.K. and McKnight, D.H. (2011) What Does It Mean to Trust Facebook? Examining Technology and Interpersonal Trust Beliefs. ACM SIGMIS Database: The DATABASE for Advances in Information Systems, 42, 32-54. https://doi.org/10.1145/1989098.1989101

[15] Grabner-Kräuter, S. (2009) Web 2.0 Social Networks: The Role of Trust. Journal of Business Ethics, 90, 505-522. https://doi.org/10.1007/s10551-010-0603-1

[16] Sheldon, P. (2009) I'll Poke You. You'll Poke Me! Self-Disclosure, Social Attraction, Predictability and Trust as Important Predictors of Facebook Relationships. Journal of Psychosocial Research on Cyberspace, 3, Article 1.

[17] Chiu, C., Hsu, M., Lai, H. and Chang, C. (2012) Re-Examining the Influence of Trust on Online Repeat Purchase Intention: The Moderating Role of Habit and Its Antecedents. Decision Support Systems, 53, 835-845.

[18] Anderson, E. and Weitz, B. (1989) Determinants of Continuity in Conventional Industrial Channel Dyads. Marketing Science, 8, 310-323. https://doi.org/10.1287/mksc.8.4.310

[19] McKnight, D.H., Cummings, L.L. and Chervany, N.L. (1998) Initial Trust Formation in New Organizational Relationships. Academy of Management Review, 23, 
473-490.

[20] Gefen, D. (2000) E-Commerce: The Role of Familiarity and Trust. Omega, 28, 725737.

[21] Bock, G., Lee, J., Kuan, H. and Kim, J. (2012) The Progression of Online Trust in the Multi-Channel Retailer Context and the Role of Product Uncertainty. Decision Support Systems, 53, 97-107.

[22] McKnight, D.H., Kacmar, C.J. and Choudhury, V. (2004) Shifting Factors and the Ineffectiveness of Third Party Assurance Seals: A Two-Stage Model of Initial Trust in a Web Business. Electronic Markets, 14, 252-266.

[23] Lu, Y., Zhao, L. and Wang, B. (2010) From Virtual Community Members to C2C ECommerce Buyers: Trust in Virtual Communities and Its Effect on Consumers' Purchase Intention. Electronic Commerce Research and Applications, 9, 346-360.

[24] Gefen, D., Karahanna, E. and Straub, D.W. (2003) Trust and TAM in Online Shopping: An Integrated Model. MIS Quarterly, 27, 51-90.

[25] Kim, D.J., Ferrin, D.L. and Rao, H.R. (2008) A Trust-Based Consumer DecisionMaking Model in Electronic Commerce: The Role of Trust, Perceived Risk, and Their Antecedents. Decision Support Systems, 44, 544-564.

[26] Zucker, L.G. (1986) Production of Trust: Institutional Sources of Economic Structure, 1840-1920. Research in Organizational Behavior, 8, 53-111.

[27] Shankar, V., Urban, G.L. and Sultan, F. (2002) Online Trust: A Stakeholder Perspective, Concepts, Implications, and Future Directions. The Journal of Strategic Information Systems, 11, 325-344.

[28] Wu, J. and Tsang, A.S. (2008) Factors Affecting Members' Trust Belief and Behaviour Intention in Virtual Communities. Behaviour \& Information Technology, 27, 115-125. https://doi.org/10.1080/01449290600961910

[29] Walczuch, R. and Lundgren, H. (2004) Psychological Antecedents of InstitutionBased Consumer Trust in E-Retailing. Information \& Management, 42, 159-177.

[30] Butler, J.K. (1991) Toward Understanding and Measuring Conditions of Trust: Evolution of a Conditions of Trust Inventory. Journal of Management, 17, 643-663. https://doi.org/10.1177/014920639101700307

[31] Bart, Y., Shankar, V., Sultan, F. and Urban, G.L. (2005) Are the Drivers and Role of Online Trust the Same for All Web Sites and Consumers? A Large-Scale Exploratory Empirical Study. Journal of Marketing, 69, 133-152. https://doi.org/10.1509/jmkg.2005.69.4.133

[32] Kim, D.J., Song, Y.I., Braynov, S.B. and Rao, H.R. (2005) A Multidimensional Trust Formation Model in B-to-C E-Commerce: A Conceptual Framework and Content Analyses of Academia/Practitioner Perspectives. Decision Support Systems, 40, 143 165.

[33] Liao, C., Palvia, P. and Lin, H. (2006) The Roles of Habit and Web Site Quality in ECommerce. International Journal of Information Management, 26, 469-483.

[34] Nicolaou, A.I. and McKnight, D.H. (2006) Perceived Information Quality in Data Exchanges: Effects on Risk, Trust, and Intention to Use. Information Systems Research, 17, 332-351. https://doi.org/10.1287/isre.1060.0103

[35] Yi, M.Y., Yoon, J.J., Davis, J.M. and Lee, T. (2013) Untangling the Antecedents of Initial Trust in Web-Based Health Information: The Roles of Argument Quality, Source Expertise, and User Perceptions of Information Quality and Risk. Decision Support Systems, 55, 284-295.

[36] Shen, Y., Huang, C., Chu, C. and Liao, H. (2010) Virtual Community Loyalty: An Interpersonal-Interaction Perspective. International Journal of Electronic Com- 
merce, 15, 49-74. https://doi.org/10.2753/JEC1086-4415150102

[37] Zolfaghar, K. and Aghaie, A. (2012) A Syntactical Approach for Interpersonal Trust Prediction in Social Web Applications: Combining Contextual and Structural Data. Knowledge-Based Systems, 26, 93-102.

[38] Gefen, D. (2004) What Makes an ERP Implementation Relationship Worthwhile: Linking Trust Mechanisms and ERP Usefulness. Journal of Management Information Systems, 21, 263-288.

[39] Wasko, M.M. and Faraj, S. (2000) "It Is What One Does": Why People Participate and Help Others in Electronic Communities of Practice. The Journal of Strategic Information Systems, 9, 155-173.

[40] Fukuyama, F. (1995) Trust: The Social Virtues and the Creation of Prosperity. Free Press, New York.

[41] Luo, X. (2002) Trust Production and Privacy Concerns on the Internet: A Framework Based on Relationship Marketing and Social Exchange Theory. Industrial Marketing Management, 31, 111-118.

[42] Morgan, R.M. and Hunt, S.D. (1994) The Commitment-Trust Theory of Relationship Marketing. Journal of Marketing, 58, 20-38. https://doi.org/10.2307/1252308

[43] Hellier, P.K., Geursen, G.M., Carr, R.A. and Rickard, J.A. (2003) Customer Repurchase Intention: A General Structural Equation Model. European Journal of Marketing, 37, 1762-1800. https://doi.org/10.1108/03090560310495456

[44] Lee, D., Lee, M. and Suh, J. (2007) Benevolence in the Importer-Exporter Relationship: Moderating Role of Value Similarity and Cultural Familiarity. International Marketing Review, 24, 657-677. https://doi.org/10.1108/02651330710832649

[45] Thorngate, W. (1976) Must We Always Think before We Act? Personality and Social Psychology Bulletin, 2, 31-35. https://doi.org/10.1177/014616727600200106

[46] Walczuch, R. and Lundgren, H. (2004) Psychological Antecedents of InstitutionBased Consumer Trust in E-Retailing. Information \& Management, 42, 159-177.

[47] Wang, E.S. and Chen, L.S. (2012) Forming Relationship Commitments to Online Communities: The Role of Social Motivations. Computers in Human Behavior, 28, 570-575.

[48] McEvily, B., Perrone, V. and Zaheer, A. (2003) Trust as an Organizing Principle. Organization Science, 14, 91-103.

[49] Tsai, W. and Ghoshal, S. (1998) Social Capital and Value Creation: The Role of Intrafirm Networks. Academy of Management Journal, 41, 464-476. https://doi.org/10.2307/257085

[50] Bargh, J.A., McKenna, K.Y. and Fitzsimons, G.M. (2002) Can You See the Real Me? Activation and Expression of the "True Self" on the Internet. Journal of Social Issues, 58, 33-48. https://doi.org/10.1111/1540-4560.00247

[51] Jiménez, N.H. and San Martín, S. (2010) The Role of Country-of-Origin, Ethnocentrism and Animosity in Promoting Consumer Trust. The Moderating Role of Familiarity. International Business Review, 19, 34-45.

[52] Wasko, M.M. and Faraj, S. (2005) Why Should I Share? Examining Social Capital and Knowledge Contribution in Electronic Networks of Practice. MIS Quarterly, 29, 35-57.

[53] Chiu, C., Hsu, M. and Wang, E.T. (2006) Understanding Knowledge Sharing in Virtual Communities: An Integration of Social Capital and Social Cognitive Theories. Decision Support Systems, 42, 1872-1888.

[54] Hwang, Y. and Kim, D.J. (2007) Customer Self-Service Systems: The Effects of Perceived Web Quality with Service Contents on Enjoyment, Anxiety, and E-Trust. De- 
cision Support Systems, 43, 746-760.

[55] McKnight, D.H., Carter, M., Thatcher, J.B. and Clay, P.F. (2011) Trust in a Specific Technology: An Investigation of Its Components and Measures. ACM Transactions on Management Information Systems (TMIS), 2, Article No. 12. https://doi.org/10.1145/1985347.1985353

[56] Horppu, M., Kuivalainen, O., Tarkiainen, A. and Ellonen, H. (2008) Online Satisfaction, Trust and Loyalty, and the Impact of the Offline Parent Brand. Journal of Product \& Brand Management, 17, 403-413. https://doi.org/10.1108/10610420810904149

[57] Komiak, S.Y. and Benbasat, I. (2006) The Effects of Personalization and Familiarity on Trust and Adoption of Recommendation Agents. MIS Quarterly, 30, 941-960.

[58] Fornell, C. and Larcker, D.F. (1981) Evaluating Structural Equation Models with Unobservable Variables and Measurement Error. Journal of Marketing Research, 18, 39-50. https://doi.org/10.2307/3151312

[59] Wetzels, M., Odekerken-Schroder, G. and Van Oppen, C. (2009) Using PLS Path Modeling for Assessing Hierarchical Construct Models: Guidelines and Empirical Illustration. MIS Quarterly, 33, 177-195.

[60] Tenenhaus, M., Vinzi, V.E., Chatelin, Y. and Lauro, C. (2005) PLS Path Modeling. Computational Statistics \& Data Analysis, 48, 159-205.

[61] Sarstedt, M., Henseler, J. and Ringle, C.M. (2011) Multigroup Analysis in Partial Least Squares (PLS) Path Modeling: Alternative Methods and Empirical Results. In: Sarstedt, M., Schwaiger, M. and Taylor, C.R., Eds., Measurement and Research Methods in International Marketing (Advances in International Marketing, Vol. 22), Emerald Group Publishing Ltd., 195-218. https://doi.org/10.1108/S1474-7979(2011)0000022012

[62] Flanagin, A.J. and Metzger, M.J. (2013) Trusting Expert- versus User-Generated Ratings Online: The Role of Information Volume, Valence, and Consumer Characteristics. Computers in Human Behavior, 29, 1626-1634.

[63] Kanagaretnam, K., Mestelman, S., Nainar, S.M. and Shehata, M. (2010) Trust and Reciprocity with Transparency and Repeated Interactions. Journal of Business Research, 63, 241-247.

[64] Manika, D., Papagiannidis, S. and Bourlakis, M. (2014) Can a CEO’s YouTube Apology Following a Service Failure win Customers' Hearts? Technological Forecasting \& Social Change, 95, 87-95. 
Submit or recommend next manuscript to SCIRP and we will provide best service for you:

Accepting pre-submission inquiries through Email, Facebook, LinkedIn, Twitter, etc. A wide selection of journals (inclusive of 9 subjects, more than 200 journals)

Providing 24-hour high-quality service

User-friendly online submission system

Fair and swift peer-review system

Efficient typesetting and proofreading procedure

Display of the result of downloads and visits, as well as the number of cited articles Maximum dissemination of your research work

Submit your manuscript at: http://papersubmission.scirp.org/

Or contact $\underline{\text { sn@scirp.org }}$ 